\title{
Astrocytic expression of HIV-1 viral protein R in the hippocampus causes chromatolysis, synaptic loss and memory impairment
}

\author{
Lilith Torres and Richard J Noel Jr
}

\begin{abstract}
Background: HIV-infected individuals are at an increased risk of developing neurological abnormalities. HIV induces neurotoxicity by host cellular factors and individual viral proteins. Some of these proteins including viral protein $\mathrm{R}$ (Vpr) promote immune activation and neuronal damage. Vpr is known to contribute to cell death of cultured rat hippocampal neurons and suppresses axonal growth. Behavioral studies are limited and suggest hyperactivity in the presence of Vpr. Thus Vpr may play a role in hippocampal loss of function. The purpose of this study is to determine the ability of HIV-1 Vpr production by astrocytes in the hippocampus to cause neurological deficits and memory impairments.
\end{abstract}

Methods: We tested the performance of rats in novel object and novel location tasks after hippocampal infusion with astrocytes expressing HIV-1 Vpr. Synaptic injury and morphological changes were measured by synaptophysin immunoreactivity and Nissl staining.

Results: Vpr-infused rats showed impaired novel location and novel object recognition compared with control rats expressing green fluorescent protein (GFP). This impairment was correlated with a significant decrease in synaptophysin immunoreactivity in the hippocampal CA3 region, suggesting synaptic injury in HIV-1 Vpr-treated animals. In addition, Nissl staining showed morphological changes indicative of neuronal chromatolysis in the Vpr group. The Vpr-induced neuronal damage and synaptic loss suggest that neuronal dysfunction caused the spatial and recognition memory deficits found in the Vpr-infused animals.

Conclusions: In this study, we demonstrate that HIV-1 Vpr produced by astrocytes in the hippocampus impairs hippocampal-dependent learning. The data suggest Vpr is a neurotoxin with the potential to cause learning impairment in HIV-1 infected individuals even under conditions of limited viral replication.

Keywords: astrocyte, synaptophysin, learning, HAND, rat model, object recognition

\section{Introduction}

The impact of HIV-1 has been moderated by the use of combination antiretroviral therapy (cART) that converts the infection from a once certain death sentence to a serious, but treatable chronic illness [1,2]. Even so, significant neuronal dysfunction has been reported in the CNS $[3,4]$ in over $50 \%$ of those infected even when viral loads are low to undetectable [5,6]. The mechanisms that mediate ongoing neurocognitive impairments in

\footnotetext{
* Correspondence: rnoel@psm.edu

Department of Biochemistry, Ponce School of Medicine and Health Sciences, P.O Box 7004, 00731 Ponce, PR, USA
}

patients on suppressive cART remain an active area of study $[7,8]$.

One of the major impediments to developing therapies that specifically target HIV-associated neurocognitive disorders (HAND) is the incomplete understanding of the mechanisms that are responsible for the development and progression of neurological impairments associated with HIV-1 infection. Macrophages and microglia represent the major productively infected cell in the brain, while astrocytes are considered to harbor a predominantly latent infection [9-14]. Particularly in patients on suppressive 
cART with undetectable plasma and cerebrospinal fluid (CSF) viremia, even low levels of viral activity in astrocytes may provide a source for viral neurotoxins. The viral burden in astrocytes, which harbor proviral DNA even during early asymptomatic infection [15], has been linked to the severity of HAND [16]. Although astrocytic infection is best characterized by limited production of early HIV-1 gene products [17-19], there are also reports supporting very low levels of replication after initial infection or by reduction of a number of host cell restriction factors [12,20-22]. Thus, in a patient on suppressive cART where replication in microglia is controlled, astrocytes are likely to have an important role in HIV neuropathology.

Astrocytes are the most abundant cell type in the brain, and they play multiple roles in brain development and normal brain functions including maintenance and regulation of neuronal cells. Evidence confirms their roles modulating neuronal signal transmission and synaptic plasticity [23-25]. Brain function may result from the combined network activity between neurons and glia. Changes in any of these interactions by HIV infection could severely impair brain homeostasis and contribute to viral neuropathology [26]. Viral replication, even at a low level, results in production of excess of viral proteins, many of which are neurotoxic. HIV-1 Vpr is a conserved HIV accessory protein involved in G2 cell cycle arrest [27] and apoptosis in human neuronal cells $[28,29]$. Vpr contributes to cell death of cultured rat hippocampal neurons [30], suppresses axonal growth [31] and causes increased intracellular calcium and plasma membrane permeability in neurons [32]. It is detected in the CSF of HIV patients [33,34]. Vpr has been found in the cytoplasm of astrocytes near areas of inflammation in HIV encephalitis indicating the potential for in vivo effects on astrocytes as well [35]. In astrocyte cultures, Vpr induces several inflammatory gene products including CCL5 [36], IL-6, IL-8, MCP-1, MIF [37], and the cyclin dependent kinase inhibitor p21/WAF1 [38]. In contrast to cellular studies of effects on astroctyes and neurons, few studies have examined whether Vpr is sufficiently neurotoxic to cause learning impairments. Vpr expression from brain monocytes in a transgenic mouse showed synaptic injury and disruption of neurotransmitter homeostatic enzymes as well as hyperexcitability and aberrant motor activity [28]. While these findings indicate that Vpr can alter CNS function, it is unknown whether Vpr expressed by astrocytes contributes to neurocognitive impairments. In this study, we established a model system to test whether Vpr produced by astrocytes can induce sufficient neurotoxicity to manifest as impaired learning. The purpose of this study is to determine the ability of HIV-1 Vpr production by astrocytes in the hippocampus to cause neurological deficits and memory impairments.

\section{Materials and methods \\ Animals}

All protocols involving rats were evaluated and approved by the Institutional Animal Care and Use Committee (IACUC). Sixty day old male Sprague Dawley rats obtained from the Ponce School of Medicine Animal Research Facilities were surgically implanted with autologous, Vprtransfected astrocytes. Primary cultures of rat astrocytes were harvested from an additional rat group, also approved by the IACUC. To deliver the Vpr-transfected (or control green fluorescent protein (GFP)-transfected) cells, we used a stereotaxic device and an infusion pump system. The infusion rate was $0.5 \mu \mathrm{L} / \mathrm{min}$ to deliver a cell content of 100,000 cells. Prior to surgery, rats were anesthetized with isoflurane. Unilateral micro-infusion of transfected primary astrocytes was performed in the dentate gyrus of the right brain hemisphere. The infusions were at the specified coordinates: AP $-0.28 \mathrm{~mm}$, ML $\pm 0.10 \mathrm{~mm}$ and DV $-0.40 \mathrm{~mm}$ from bregma. Infusions were performed using a published protocol $[39,40]$ with modifications [41]. After two days of recovery, rats were tested in the novel location and novel object recognition learning task (details follow). Following behavioral testing, rats were euthanized with an overdose of pentobarbital, blood was removed by cardiac puncture and animals were perfused with saline followed by buffered formalin to preserve brain tissue for analyses. The proper location of the infusion site was determined histologically. Throughout the experiments, rats were maintained on a 12-hour day/night cycle with free access to food and water.

\section{Transient transfection of primary astrocytes}

Primary astrocytes were isolated from Sprague Dawley rats $[41,42]$ and cultured in DMEM with $10 \%$ fetal bovine serum. Transfection was used as a way to deliver the plasmid-encoding viral protein $\mathrm{Vpr}$ to stimulate the cell protein production. Primary rat astrocytes were transfected with a plasmid-encoding Vpr-GFP (experimental group) and GFP (control). Transfections were done using the Gene Pulser Xcell Electroporation System (Bio-Rad, Hercules, CA, USA) under the following conditions: $4 \mathrm{~mm}$ cuvette containing 5 ug of plasmid DNA per $1.6 \times 10^{6}$ cells in a $300 \mu \mathrm{l}$ volume of serum-free RPMI; $250 \mathrm{~V}$ and $35 \mathrm{~ms}$ using a time constant protocol. Flow cytometry was done using a GFP plasmid to determine transfection efficiency. Routine transfection efficiency by GFP expression was between 60 and $80 \%$ positive cells.

\section{Vpr mRNA and protein detection}

Total RNA and protein were isolated from transfected cells after various times in culture using Nucleospin reagents and protocol (Macherey-Nagel, Bethlehem, PA, USA). RNA ( $1 \mu \mathrm{g})$ was converted to cDNA using the Bio- 
Rad iScript cDNA synthesis kit, followed by 35 cycles of real-time PCR with the Bio-Rad SYBR-green Supermix. The GFP control transfections produced only background fluorescence values, precluding a fold-change comparison; thus, relative expression of $\mathrm{Vpr}$ was determined by comparing signal strength versus the housekeeping gene, $\beta$-actin, and the difference in cycle of detection $(\Delta \mathrm{Ct})$ is reported. Western blotting was used to confirm $\mathrm{Vpr}$ protein expression; $25 \mu \mathrm{g}$ of protein from each total cell lysate were separated by SDS-PAGE and transferred to PVDF membranes. Membranes were incubated overnight at $4^{\circ} \mathrm{C}$ with primary antibody rabbit anti-Vpr (AIDS Research and Reference Reagent Program, NIH; Cat. \#11836; 1:500) or anti-actin (Sigma, St. Louis, MO, USA; Cat. \#A5060; 1:1000) Detection of bound primary antibodies was achieved with horseradish peroxidase (HRP)-conjugated secondary antibody followed by chemiluminescent/ chemifluorescent detection (General Electric RJP 2332).

\section{Novel location and novel object learning task}

Novel location and object recognition tasks were performed after infusion of astrocytes expressing HIV-1 Vpr or GFP. The protocol was adjusted from Benice and colleagues [43]. These experiments start by handling the rats to provide a period for adjustment to manipulation by humans and to reduce stress that could interfere with the behavioral test. Rats were handled for 5 minutes daily over four days, prior to brain surgery (day 5). After brain surgery and a 2-day recovery period, rats began training and testing. Training consisted of a day of habituation where the rats are familiarized with the open field that is used for testing. Rats were placed in a square box ( $9 \mathrm{sq}$. $\mathrm{ft}$. area) for two trials of 5 minutes, each separated by 1 hour. On the following day, three objects were placed at specific locations within the same open field. Rats were then trained to learn the object locations through three 5-minute exposure periods, separated by 1 -hour intervals. After 24 hours, one object was moved to the opposite corner (new location) and then the rat was given a 5-minute challenge to test memory of the old location. Memory was indicated by the rat spending additional time exploring the new location as rats will preferentially explore novelty when presented with a familiar environment. One hour later, one of the two unmoved objects was replaced (new object). The rat was given a 5 -minute challenge to assess memory of old objects. The test measured exploration time for all objects, with learning indicated by a preference for the new object. Animals that did not show preference for novelty in either test were considered to have a memory deficit. Data acquisition was by a digital video camera followed by analysis with Ethovision software (Noldus Information Technology Inc., Leesburg, VA, USA).

\section{Nissl staining for assessment of chromatolysis and neuronal damage}

After sacrifice, brains were removed and preserved in buffered formalin prior to paraffin embedding. Brain slices of $4 \mu \mathrm{m}$ thickness were dewaxed in xylene substitute followed by rehydration with graded ethanol from $100 \%$ to $50 \%$. Slides were incubated in distilled water, stained in thionin solution, rinsed and incubated in 50\% ethanol. Slides were placed in a solution of $70 \%$ ethanol and 95\% acetic acid. Final incubations were in 95\% ethanol and twice in $100 \%$ ethanol solution. The slides were dipped in xylene twice. Then permount and a cover slide were added. Photos were taken using a digital camera and an Olympus microscope; images were analyzed using NIS Elements software.

\section{Immunohistochemistry for assessment of synaptic injury}

To examine changes in synaptophysin between control and HIV-1 Vpr exposed rats, tissue sections from each group were processed for immunocytochemistry. The samples were cut at $4 \mu \mathrm{m}$ thickness with a microtome (Microm HM340, Microm International) and fixed to positively charged microscope slides. Fixed tissues were deparaffinized in xylene substitute for 30 minutes, rehydrated through graded alcohols and neutralized with $3 \%$ hydrogen peroxide (Sigma-Aldrich), followed by a rinse under running tap water and immersion in antigenretrieval solution $(0.01 \mathrm{M}$ citrate, $\mathrm{pH}$ 6.0) for 1 minute at $98^{\circ} \mathrm{C}$. Then sections were washed in TBS for 5 minutes and treated with blocking solution containing normal goat serum (BioGenex, cat\# HK112-9KE). Sections were incubated for $24 \mathrm{hrs}$ at $4^{\circ} \mathrm{C}$ in mouse monoclonal antisynaptophysin antibody (Neuromics, cat \# MO20000, 1:500 dilutions). Negative controls with TBS instead of primary antibody were run in each slide. Primary antibody was washed in TBS buffer for $2 \times 5$ minutes and incubated with Multi Link secondary antibody (Super Sensitive Link-Label IHC Detection System, cat\# LP000ULE, BioGenex, San Ramon, CA, USA). Secondary antibody was washed in TBS and incubated in ABC-HRP, washed in TBS buffer and incubated in 3,3'-diaminobenzidine (cat\# HK153-5KE, Biogenex, San Ramon, CA, USA). Slides were rinsed in water and counterstained with hematoxylin for $30 \mathrm{sec}$. The sections were rinsed, dehydrated and mounted with Cytoseal XYL (cat\# 8312-4, Richard Allan Scientific, Kalamazoo, MI, USA). For quantitative densitometry, images of regions of interest (ROI) in the CA3 were captured from 5 rats in each group using NIH Image J 1.50 software.

\section{Statistical analysis}

Statistical analyses were done with Graph Pad Prism version 5.02. ANOVA was used to measure statistics of locomotor activity, center zone time, and time spent 
exploring novelty within group Vpr and GFP, as well as analyses of $\mathrm{Vpr}$ expression and of differences in chromatolysis and synaptophysin. Statistical comparisons of time spent exploring new location/object between $\mathrm{Vpr}$ and GFP were done using the Student $t$ test. $P$ values $\leq 0.05$ were considered significant.

\section{Results}

As a preliminary step in generating a rat model of spatial learning impairment by endogenous expression of HIV-1 Vpr protein from astrocytes, we established a primary astrocyte cell culture system. Cells were cultured in vitro as previously described [41] and genetically modified to express Vpr from a plasmid by transfection. Figure 1A demonstrates that primary rat astrocytes strongly express the Vpr gene for at least 7 days post-transfection in vitro compared to control cells that were mock transfected. The mRNA levels for Vpr were substantial at several thousandfold over background at all time points as assessed by realtime RT-PCR. A no-RT control showed background levels equivalent to the control cells (not shown) indicating the signal was from RNA and not from transfected plasmid. Vpr protein expression in vitro peaked rapidly and declined after 48 hours. The peak expression as determined by western blot occurs immediately after transfection at 6 hours (Figure 1B). Thus, while mRNA levels were continuously expressed, protein was detectable for a shorter duration; consistent with this in vitro finding, we were unable to detect $\mathrm{Vpr}$ protein at the time of sacrifice (data not shown). Difficulty in detecting Vpr protein in vivo has been reported [28] even when the toxic effects of Vpr are present.

\section{Normal locomotor, anxiety and weight changes during learning session}

To define any physical or behavioral interference during the learning task, we analyzed the distance traveled (locomotor function) and the percent of time the rats spent in the center (assessment of anxiety) in an open field test. In order to examine spatial learning, the first step was to familiarize the rats with the environment. Exposure to a new environment leads to habituation characterized by a large amount of initial exploratory activity and a subsequent decrease as the rats become familiar with the environment $[44,45]$. In our experimental design, the initial exposure to objects in the open field was where this type of habituation during learning occurred. We measured distance traveled during the trials of the acclimation phase. Animals in both groups showed a similar trend of reduction in exploration across subsequent trials (Figure 2A). While Vpr animals traveled less distance in each trial, they showed the same tendency of reduced exploration from trial 1 to trial 2 and trial 2 to trial 3 as the GFP group. This demonstrates that the Vpr rats habituated and were able to familiarize with the objects and learning environment. The groups did not show differences in anxiety as indicated by the increased time spent passing through the center zone of the open field with each exposure to the environment (Figure 2B). Finally, the neurotoxicity of $\mathrm{Vpr}$ we detected in the chromatolytic neurons did not affect the overall health of the rats as assessed by weight gain (Figure 2C). Based on these parameters, the rats from both the Vpr and GFP groups were able to adequately perform our tests of novel recognition without influence from motor, anxiety or general health impairments. Thus, we proceeded with the test of novelty recognition.

\section{Vpr expression in the hippocampus impairs long-term memory}

Hippocampal function (learning) can be compromised by neuronal damage or death caused by exposure to Vpr. In order to test for deficits in learning and memory due to neuron disruption driven by Vpr neurotoxicity,

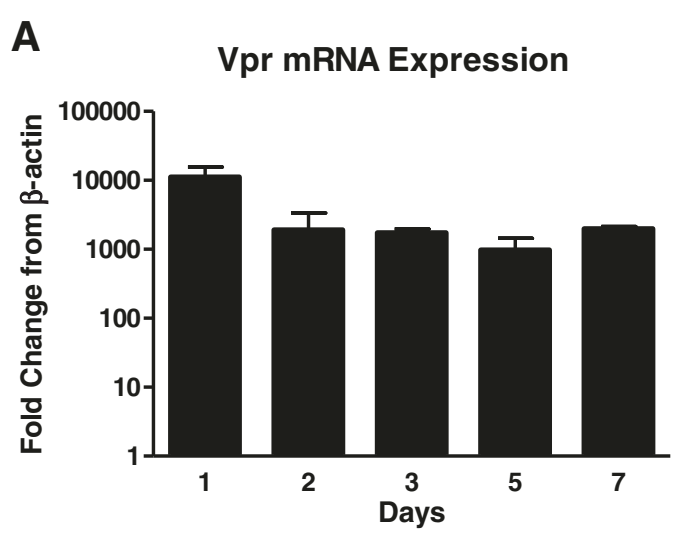

B
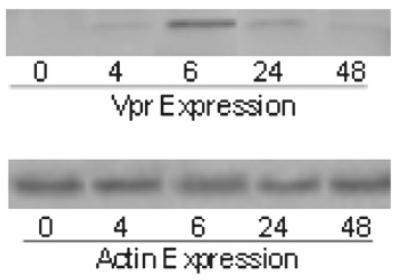

( maintained in culture over 7 days as determined by real time RT-PCR. Relative expression versus controls lacking Vpr are presented. $\beta$-actin was used as the normalization control. (B) Vpr protein peaks at 6 hours after transfection and remains detectable for 48 hours in culture as determined by western blotting. 
A
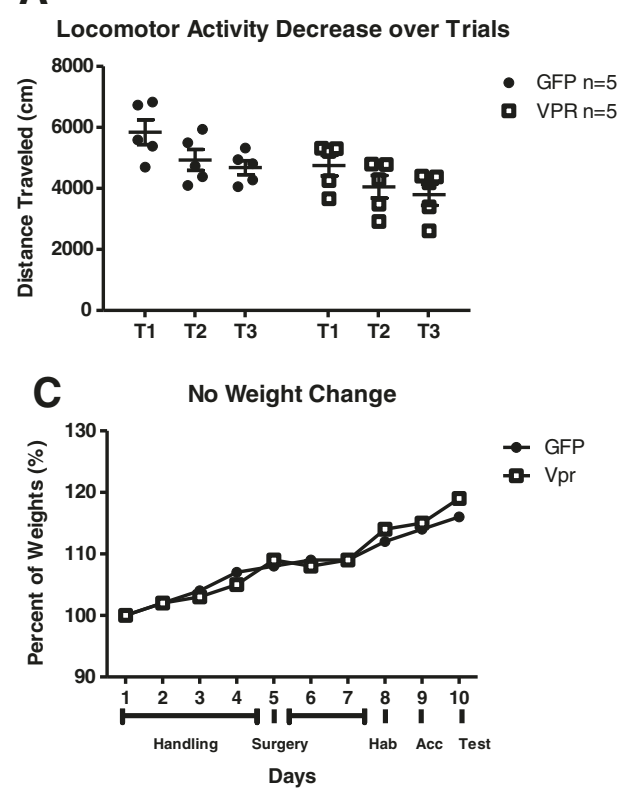

B

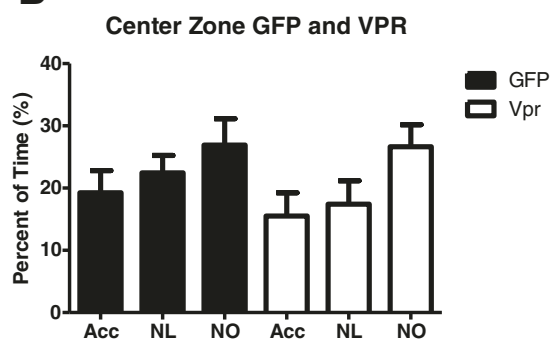

Figure 2 Normal locomotor, anxiety and weight changes during learning session. (A) Decreased distance traveled across trials shows that both groups successfully acclimated and were familiar with the environment. (B) Time spent in the center zone during the behavior was not altered by treatment, showing that viral protein R (Vpr) did not affect anxiety. (C) Normal rat weight (grams) gain shows no difference throughout the experiment or by treatment. Acc, acclimation; NL, novel location; NO, novel object.

we measured behavioral responses to spatial change. While the rats habituate and learn the objects, a process of recognition and identification leading to prioritized attention to unexpected or new information develops [45]. This is shown when a change in spatial configuration provokes an increase in exploratory activity of the novelty. The rats exhibit a preference for the change or moved object. Spatial memory (novel location learning) and episodic memory (novel object learning) were assessed by comparing the time exploring the static object and the time exploring the moved or changed object. We determined the potential of Vpr to cause learning deficits by comparison against control animals infused with GFP-expressing astrocytes. Animals in the Vpr group showed deficits in both spatial and episodic memory by failing to increase exploration of the object in the new location and new object, respectively (Figure 3A). In contrast, GFP-treated rats displayed a trend $(P=0.0607)$ of increased exploration of the new location and statistically increased exploration of the novel object $(P<0.05)$. To substantiate that the changes in exploration represented different behavior between the groups, we also made direct comparisons between the GFP- and Vpr-treated rats for their exploration of novelty. Figure 3B shows that GFP rats explored the novel location statistically more than their Vpr-treated counterparts $(P=0.0011)$. Together these results indicate a significant spatial learning impairment is caused by endogenous Vpr expression.
Astrocyte expression of HIV-1 Vpr in the hippocampus induces structural changes indicating damage to neurons Astrocytes respond to viral neurotoxins by releasing proinflammatory molecules, which attract macrophages and induce apoptosis of bystander cells [46,47]. HIV Vpr is known to produce apoptosis in several types of cells including human neurons $[28,29,37,46,48]$. We used Nissl staining to assess neuronal morphology. Our results show that rats infused with Vpr-transfected astrocytes develop chromatolytic neuronal morphology in CA3 and CA1 (Figure 4A). We found a significant difference in number of chromatolytic cells and normal cells present in the CA1 and CA3 (Figure 4B). Chromatolysis is characterized by transient enlargement of the nucleus and cell body, reorganization of rough endoplasmic reticulum, and gradual disappearance of Nissl bodies by loss of RNA basophilic staining [49-52] Neuronal recovery through regeneration can occur after chromatolysis [53], but most often it is a precursor of cell death or apoptosis. TUNEL staining of brain slices from these rats did not show reactivity (data not shown), indicating that the chromatolysis in our model does not induce neuronal death. We also looked for activation of caspase 3/7 and Annexin V assay in astroctyes transfected with $\mathrm{Vpr}$ in vitro and did not observe signs of apoptosis (data not shown).

Since chromatolysis may reflect damage to neurons that is below the threshold to cause apoptosis, we examined the brain tissue for signs of synaptodendritic injury. 


\section{A}

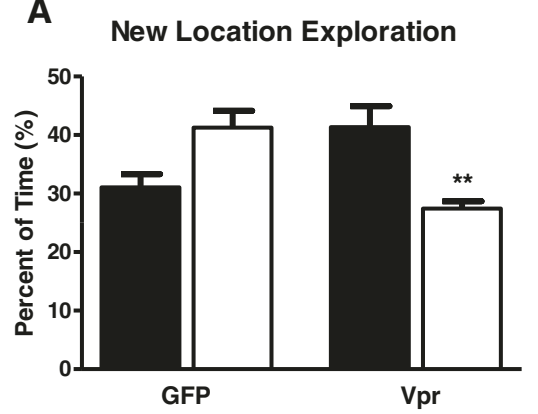

$$
\text { B }
$$
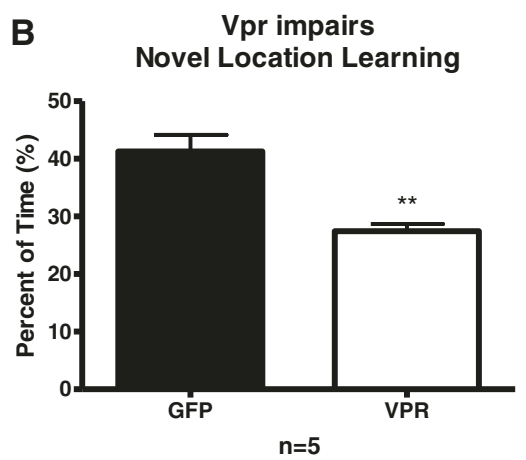

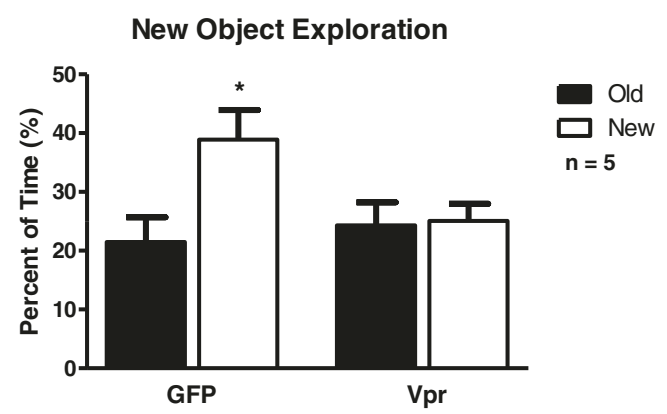

Vpr impairs Novel Object Learning

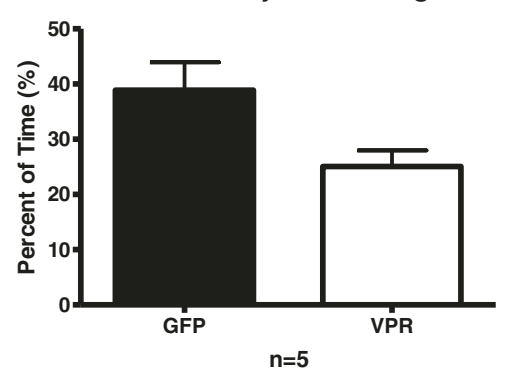

Figure 3 HIV-1 viral protein R (Vpr) expression in the hippocampus causes memory impairment. (A) Exploration time show a significant difference in learning for the control group (green fluorescent protein, GFP) and significant learning impairment for the experimental group (Vpr). Exploration time of the replacement with a novel object, show significant learning for the control group (GFP) and the familiar object show impaired learning for the experimental group (Vpr). Significance was assessed by ANOVA. ${ }^{*} P<0.05$, ${ }^{* *} P<0.01$. (B) Significant difference in object exploration at the novel location ( $t$ Test $P<0.0011$ ). Control group (GFP) shows preference for the novel location and the novel object.

Since deletion of the major presynaptic terminal protein, synaptophysin, produces impairment in tests of object novelty and spatial learning in mice [54], we examined whether infusion of the Vpr-expressing astrocytes affected synaptophysin expression in the hippocampus. We found a significant reduction in synaptophysin staining in CA3, particularly on the infusion side (Figure 5). Thus, even though we found no evidence of neuronal death by apoptosis, the overall cellular morphology showed significant damage and increased chromatolysis that upon closer examination showed signs of synaptic injury and loss of a major synaptic protein.

\section{Discussion}

HIV invasion into the brain promotes cellular responses causing neurological impairments that affect cognition, behavior and motor function $[5,26,47,55]$. In this study, we report the contributions of HIV-1 Vpr to hippocampal loss of function and neurocognitive impairment. HIV-1 Vpr produced by astrocytes in the hippocampus impairs memory and causes damage to neurons resulting in synaptic injury without detectable apoptosis. Our results support that limited viral protein production by astrocytes is sufficient to produce toxicity and functional impairment of neurons.

HIV-1 Vpr has been found in several infected cell types in the brain including astrocytes [35]. Although astrocytes show low permissiveness to HIV-1 infection [9,56,57], more recent work indicates astrocyte infection is substantially greater in HIV patients with dementia [16]. Astrocytes participate in extensive neuron-glial synaptic interactions [58] and are involved in synaptic plasticity $[59,60]$. Memory and synaptic plasticity have been always attributed to neuronal modulation. As reviewed by Ota [61], evidence shows that astrocytes have an ongoing role in the regulation of neuronal activity through the release of gliotransmitters and modification of postsynaptic neurons. In the hippocampus, $62 \%$ of synapses are contacted by astrocytes at the synaptic cleft [62]. Thus, even with low permissiveness, astrocyte infection could have significant effects and contribute to HAND.

The recognition that HAND occurs even when viral loads in plasma and CSF are undetectable suggests that viral activity and chronic inflammation are present during suppressive cART $[5,8]$. The brain serves as a reservoir for HIV and represents a site in which this residual 

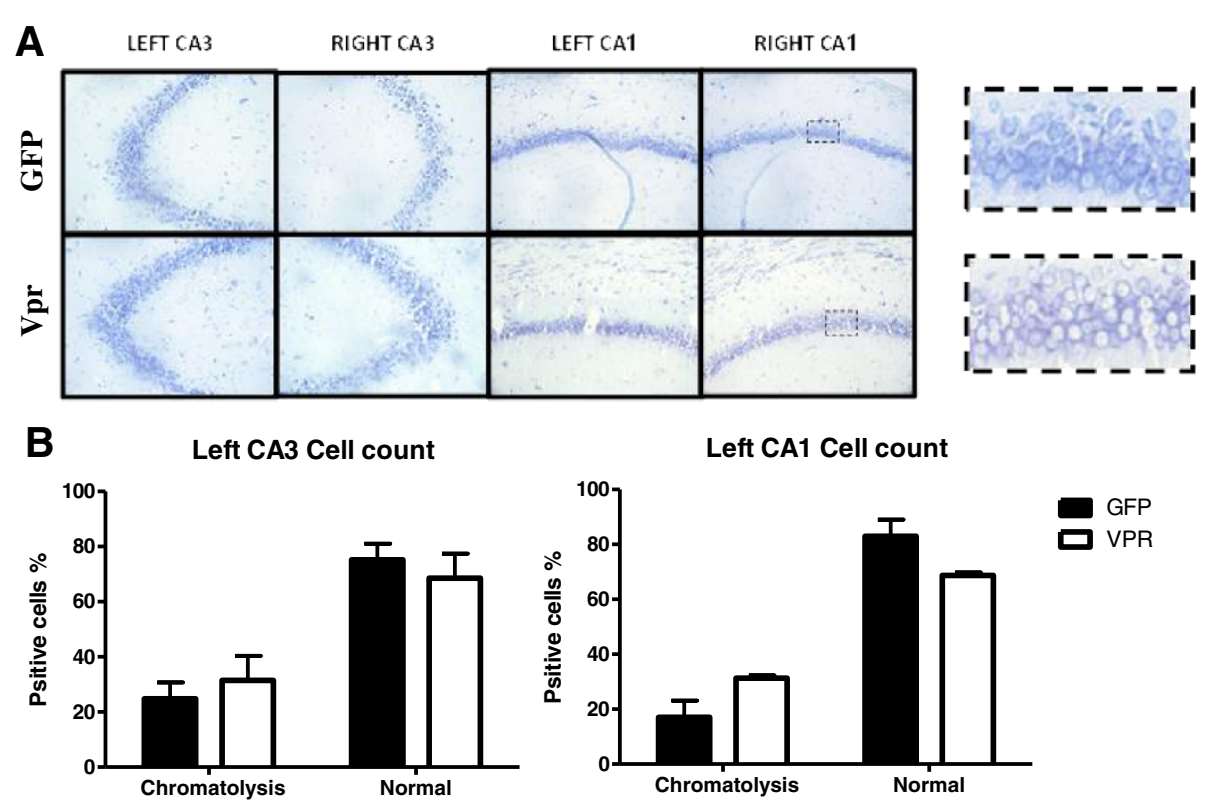

Right CA3 Cell count

Right CA1 Cell count
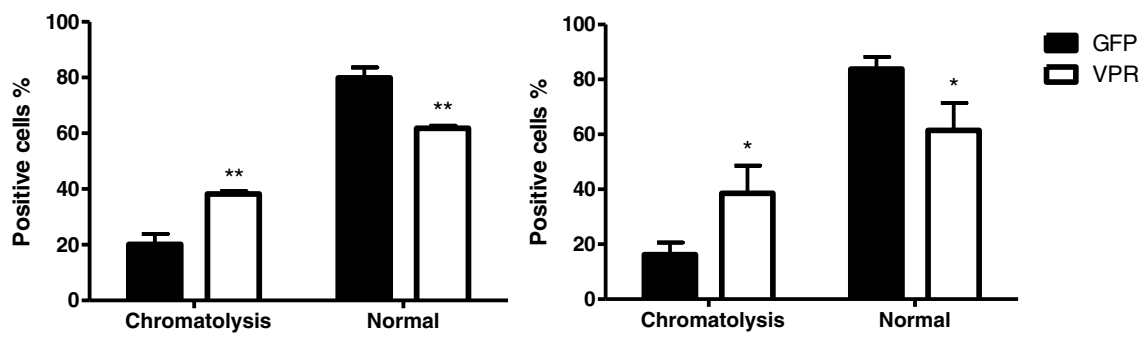

Figure 4 Astrocytic HIV-1 viral protein R (Vpr) production induces neuronal chromatolysis. (A) Representative 40x images of the Nissl stained hippocampal sections show reduced staining in Vpr-treated tissues. Chromatolysis was detected by prominent migration of the nucleus toward the periphery of the cell (shown in zoom to right). (B) Normal and chromatolytic neurons were counted from three sections per rat in CA1 and CA3 of both hippocampal hemispheres of green fluorescent protein (GFP)- and Vpr-treated rats. Mean and standard deviation are graphed. Significance was assessed by ANOVA. ${ }^{*} P<0.05,{ }^{*} P<0.01$. Five rats were counted in each group.

viral activity continues [63]. HIV-1 Vpr is most likely produced in astrocytes where limited viral activity is stimulated by inflammation [21], resulting in localized effects. Our model simulates focal Vpr production by astrocytes in the hippocampus to examine if the toxic effect is sufficient to damage neurons both physically and functionally using histological analyses and behavioral testing. Vpr-treated rats, in comparison to their GFPtreated counterparts, were subjected to a 5-day protocol that resulted in impaired novelty recognition. Interestingly, although the Vpr gene expression was detectable at the RNA level across the duration, Vpr protein was detectible only transiently, indicating that a short exposure produces a pathological phenotype. Rats in both groups were able to demonstrate working memory of the testing chamber as demonstrated by reduction in exploration across three consecutive sessions to learn the object locations. Failure to learn the objects in this manner would constitute a short-term learning deficit.
During acclimation to the open field, the rats construct a cognitive map of the objects and the environment that allows them to detect changes. If they are impaired they are unable to associate the spatial changes in the learning cage [64]. Interestingly, another study where $\mathrm{Vpr}$ was expressed transgenically in monocyte cells showed neurotoxic effects [28]. Vpr expression, in brain tissue, particularly in basal ganglia and cortex, was detected at the RNA level but as with our experiments, Vpr protein immunoreactivity was difficult to document [28]. In our model, Vpr treated rats show an overall reduction in distance (Figure 2A). In addition to distance traveled, we also measured time spent in center zone. Avoidance of the center zone indicates anxiety during the exposure to the open field [65]. Time in center zone was measured to assess Vpr's effect on anxiety. We found minimal differences between the groups allowing us to exclude anxiety as a cause of the impaired memory (Figure 2B). Finally, as we reported in a similar 

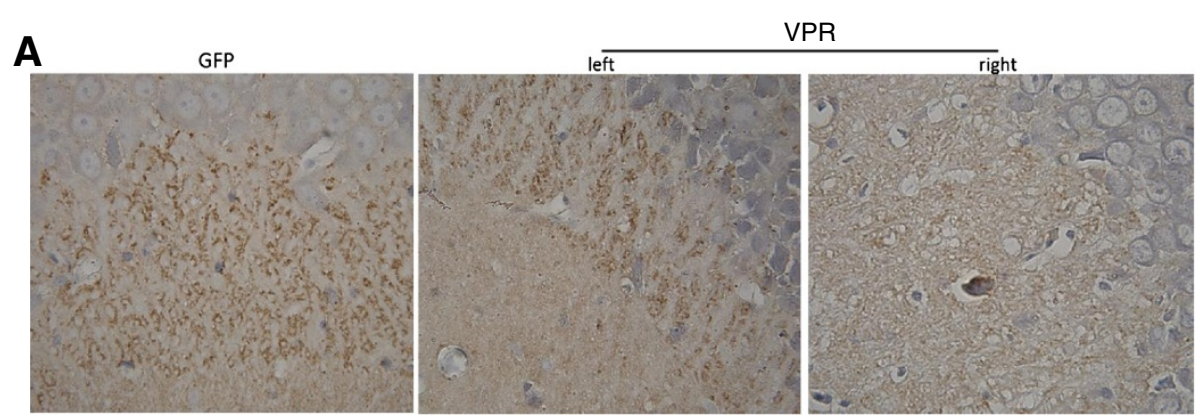

\section{B CA3 Synaptophysin}

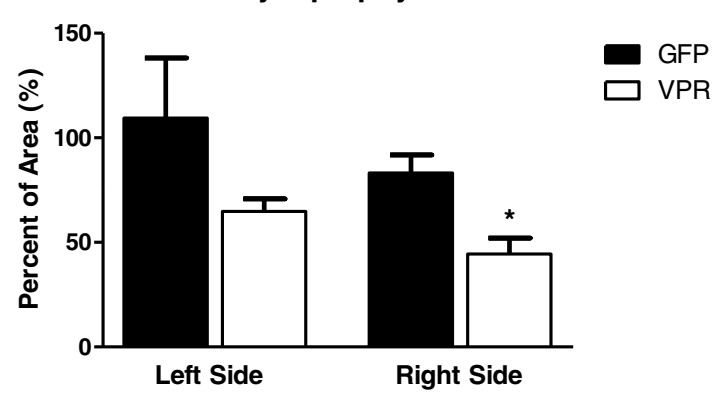

Figure 5 Astrocytic HIV-1 viral protein R (Vpr) expression decreased synaptophysin immunoreactivity. (A) Representative light photomicrograph showing the distribution of synaptophysin immunoreactivity in the rat hippocampal CA3 formation. Green fluorescent protein (GFP) right side. Vpr shows both left and right. Magnification 100x. (B) Densitometric analysis revealed significantly decreased mean value for the Vpr group compare to control. Significance was assessed by ANOVA. ${ }^{*} P<0.05$ Graph shows mean plus standard deviation. $N=5,3$ images per rat.

study using Nef as the neurotoxin [41], we found that Vpr treatment does not affect general health as measured by weight gain (Figure 2C).

Our results correlate memory loss with neuronal chromatolysis in hippocampal CA3 region. Chromatolysis is typically seen in response to axonal injury and refers to the dissolution of Nissl bodies in the cytoplasm [66]. It is considered an early stage of morphological pathology that occurs in a cell that may enter apoptosis. Chromatolytic morphological changes have not been well explained, and there is a controversy as to whether chromatolytic neurons are irreversibly destined for death or if neurons may recover from injury marked by chromatolysis $[52,53,67]$. Chromatolysis is often observed as a consequence of axonal injury $[68,69]$. Some studies report that a cell undergoing chromatolysis activates regenerative pathways later, increasing protein production to counteract neuronal insults [70]. Redirecting cell machinery for regeneration can compromise metabolic needs and productivity that would otherwise be available for learning.

The hippocampus is involved in object recognition and memory formation [71]. To investigate the molecular mechanisms involved in HIV-1 Vpr induced memory impairment, we examined hippocampal levels of synaptophysin. Memory impairment was associated with decreased hippocampal synaptophysin in a mice model of Alzheimer
[72]. As well, transgenic mice without synaptophysin demonstrate spatial and novelty learning impairments. Interestingly, these mice also demonstrate increased exploratory activity that is indicative of failure to habituate. Our Vpr-treated rats were able to habituate effectively, but like the transgenic mice lacking synaptophysin, demonstrated novelty learning impairment [54]. A major caveat to comparing these studies is that the transgenic mice had a complete absence of synaptophysin in all neurons and throughout development, whereas our Vpr rats showed decreased synaptophysin staining in a localized region for a short duration. This may explain why our rats showed habituation.

The CA3 is known to be associated with spatial learning, novelty detection, and short-term memory [73]. It is divided into CA3-a, -b, and -c subareas [74] CA3-a and $-\mathrm{b}$, play important roles in new spatial information and short term memory [75]. As demonstrated in our results, the CA3-a region showed decreased synaptophysin staining that correlated with the learning and memory impairment found in the novel recognition spatial learning task. Synaptophysin plays an important role in modulating synaptic plasticity. Alterations to the metabolic needs of the cell may compromise consolidation process leading to a learning and memory impairment. Synaptophysin is a synaptic vesicle specific protein, present in the membrane 
of neuronal presynaptic vesicles [76,77]. It is implicated in the control of exocytosis [78] and neurotransmitter release [79]. Studies have shown increased synaptophysin in enriched environments with improved spatial memory [80]. These results demonstrate that HIV-Vpr expression in the hippocampus induces a synaptic impact with marked reductions in presynaptic synaptophysin protein involved in neurotransmission and synaptic plasticity.

\section{Conclusions}

We report for the first time that Vpr produced endogenously from astrocytes from a discrete region (right hemisphere dentate gyrus) and short duration (five days or fewer) causes neurotoxicity that is both morphologically and functionally relevant. The functional impairment is specific for spatial and episodic memory and does not represent a generalizable impairment as animals demonstrate proper motor function as well as the capacity for short term learning. The impairment manifests at least in part from neuronal injury and synaptic damage specifically in the hippocampus. The absence of apoptotic cells suggests that the damage caused by transient expression of $\mathrm{Vpr}$ is not permanent. In some respects, this is akin to recovery in function shown by some patients upon starting suppressive therapy. However, our model does not address the issue of the impact of multiple, sporadic (temporal and anatomical) insults that could be caused by focal viral neurotoxin production. These events when summed over time may be at the foundation for the observed continued progression of HAND in treated HIV1 infected populations. Our results provide a basis for the importance of sub-replication viral activity which may occur from atypically infected cells, like astrocytes, in the continued neurological morbidities affecting those infected with HIV-1 in the era of suppressive antiretroviral therapy.

\section{Abbreviations \\ CART: combination antiretroviral therapy; CNS: central nervous system: CSF: cerebrospinal fluid; GFP: green fluorescent protein; HAND: \\ HIV-associated neurocognitive disorders; Vpr: viral protein R.}

\section{Competing interests}

The authors declare that they have no competing interests.

\section{Author's contribution}

LT performed the experiments. LT and RJN designed the study, analyzed the data and wrote the manuscript. Both authors read and approved the final manuscript.

\section{Acknowledgements}

Research supported by DA026722 and GM106970 as well as the Ponce School of Medicine and Health Sciences Molecular and Genomics Core (MD007579) and the Ponce School of Medicine and Health Sciences Behavioral Research and Integrative Neuroscience Core (MD007579). Critical review of the manuscript was kindly provided by Dr. James T. Porter (Ponce School of Medicine), Dr. Vanessa Rivera (Ponce School of Medicine), and Dr. Susan M Barman (Michigan State University, through the American Physiological Society writing and reviewing for scientific journals course). We acknowledge Elizabeth Rivera, Lucianette Maldonado Eliezer Ruiz, Maria
Colon and Myrella Cruz for technical assistance. We are grateful to Dr. Annelyn Torres (PSMHS) and Dr. Shilpa Buch (Univ. of Nebraska Med. Center) for scientific input.

Received: 28 January 2014 Accepted: 24 February 2014

Published: 22 March 2014

\section{References}

1. Mocroft A, Ledergerber B, Katlama C, Kirk O, Reiss P, d'Arminio MA, Knysz B, Dietrich M, Phillips AN, Lundgren J: Decline in the AIDS and death rates in the EuroSIDA study: an observational study. Lancet 2003, 362:22-29.

2. Panos G, Samonis G, Alexiou VG, Kavarnou GA, Charatsis G, Falagas ME: Mortality and morbidity of HIV infected patients receiving HAART: a cohort study. Curr HIV Res 2008, 6:257-260.

3. Giometto B, An SF, Groves M, Scaravilli T, Geddes JF, Miller R, Tavolato B, Beckett AA, Scaravilli F: Accumulation of beta-amyloid precursor protein in HIV encephalitis: relationship with neuropsychological abnormalities. Ann Neurol 1997, 42:34-40.

4. An SF, Giometto B, Groves M, Miller RF, Beckett AA, Gray F, Tavolato B, Scaravilli F: Axonal damage revealed by accumulation of beta-APP in HIV-positive individuals without AIDS. J Neuropathol Exp Neurol 1997, 56:1262-1268.

5. McArthur J, Smith B: Neurologic complications and considerations in HIV-infected persons. Curr Infect Dis Rep 2013, 15:61-66.

6. Heaton RK, Clifford DB, Franklin DR Jr, Woods SP, Ake C, Vaida F, Ellis RJ, Letendre SL, Marcotte TD, Atkinson JH, Rivera-Mindt M, Vigil OR, Taylor MJ, Collier AC, Marra CM, Gelman BB, MCArthur JC, Morgello S, Simpson DM, McCutchan JA, Abramson I, Gamst A, Fennema-Notestine C, Jernigan TL, Wong J, Grant I, CHARTER Group: HIV-associated neurocognitive disorders persist in the era of potent antiretroviral therapy: CHARTER Study. Neurology 2010, 75:2087-2096.

7. Tozzi V, Balestra P, Bellagamba R, Corpolongo A, Salvatori MF, ViscoComandini U, Vlassi C, Giulianelli M, Galgani S, Antinori A, Narciso P. Persistence of neuropsychologic deficits despite long-term highly active antiretroviral therapy in patients with HIV-related neurocognitive impairment: prevalence and risk factors. J Acquir Immune Defic Syndr 2007, 45:174-182

8. Heaton R, Franklin D, Ellis R, McCutchan J, Letendre S, LeBlanc S, Corkran S, Duarte N, Clifford D, Woods S, Collier AC, Marra CM, Morgello S, Mindt MR, Taylor MJ, Marcotte TD, Atkinson JH, Wolfson T, Gelman BB, McArthur JC, Simpson DM, Abramson I, Gamst A, Fennema-Notestine C, Jernigan TL, Wong J, Grant I, CHARTER Group; HNRC Group: HIV-associated neurocognitive disorders before and during the era of combination antiretroviral therapy: differences in rates, nature, and predictors. J Neurovirol 2011, 17:3-16.

9. Trillo-Pazos G, Diamanturos A, Rislove L, Menza T, Chao W, Belem P, Sadiq S, Morgello S, Sharer L, Volsky DJ: Detection of HIV-1 DNA in microglia/ macrophages, astrocytes and neurons isolated from brain tissue with HIV-1 encephalitis by laser capture microdissection. Brain Pathol 2003, 13:144-154

10. Tornatore C, Nath A, Amemiya K, Major EO: Persistent human immunodeficiency virus type 1 infection in human fetal glial cells reactivated by T-cell factor(s) or by the cytokines tumor necrosis factor alpha and interleukin-1 beta. J Virol 1991, 65:6094-6100.

11. Price RW, Brew B, Sidtis J, Rosenblum M, Scheck AC, Cleary P: The brain in AIDS: central nervous system HIV-1 infection and AIDS dementia complex. Science 1988, 239:586-592.

12. Messam CA, Major EO: Stages of restricted HIV-1 infection in astrocyte cultures derived from human fetal brain tissue. J Neurovirol 2000, 6(Suppl 1):S90-S94.

13. He J, Chen Y, Farzan M, Choe H, Ohagen A, Gartner S, Busciglio J, Yang X, Hofmann W, Newman W, Mackay CR, Sodroski J, Gabuzda D: CCR3 and CCR5 are co-receptors for HIV-1 infection of microglia. Nature 1997, 385:645-649.

14. Ghorpade A, Nukuna A, Che M, Haggerty S, Persidsky Y, Carter E, Carhart L, Shafer L, Gendelman HE: Human immunodeficiency virus neurotropism: an analysis of viral replication and cytopathicity for divergent strains in monocytes and microglia. J Virol 1998, 72:3340-3350.

15. Thompson KA, Cherry CL, Bell JE, McLean CA: Brain cell reservoirs of latent virus in presymptomatic HIV-infected individuals. Am J Pathol 2011, 179:1623-1629. 
16. Churchill MJ, Wesselingh SL, Cowley D, Pardo CA, McArthur JC, Brew BJ, Gorry PR: Extensive astrocyte infection is prominent in human immunodeficiency virus-associated dementia. Ann Neurol 2009, 66:253-258.

17. Tornatore C, Chandra R, Berger JR, Major EO: HIV-1 infection of subcortical astrocytes in the pediatric central nervous system. Neurology 1994, 44:481-487.

18. Ranki A, Nyberg M, Ovod V, Haltia M, Elovaara I, Raininko R, Haapasalo H, Krohn K: Abundant expression of HIV Nef and Rev proteins in brain astrocytes in vivo is associated with dementia. AIDS 1995, 9:1001-1008.

19. Brack-Werner R, Kleinschmidt A, Ludvigsen A, Mellert W, Neumann M, Herrmann R, Khim MC, Burny A, Muller-Lantzsch N, Stavrou D, et al: Infection of human brain cells by HIV-1: restricted virus production in chronically infected human glial cell lines. AIDS 1992, 6:273-285.

20. Vincendeau M, Kramer S, Hadian K, Rothenaigner I, Bell J, Hauck SM, Bickel C, Nagel D, Kremmer E, Werner T, Leib-Mösch C, Brack-Werner R: Control of HIV replication in astrocytes by a family of highly conserved host proteins with a common Rev-interacting domain (Risp). AIDS 2010, 24:2433-2442

21. Li W, Henderson $\sqcup$, Major EO, Al-Harthi L: IFN-gamma mediates enhancement of HIV replication in astrocytes by inducing an antagonist of the beta-catenin pathway (DKK1) in a STAT 3-dependent manner. $\mathrm{J}$ Immunol 2011, 186:6771-6778.

22. Tornatore C, Meyers K, Atwood W, Conant K, Major E: Temporal patterns of human immunodeficiency virus type 1 transcripts in human fetal astrocytes. J Virol 1994, 68:93-102.

23. Halassa MM, Haydon PG: Integrated brain circuits: astrocytic networks modulate neuronal activity and behavior. Annu Rev Physiol 2010, 72:335-355.

24. Perea G, Navarrete M, Araque A: Tripartite synapses: astrocytes process and control synaptic information. Trends Neurosci 2009, 32:421-431.

25. Navarrete M, Perea G, Fernandez de Sevilla D, Gomez-Gonzalo M, Nunez A, Martin ED, Araque A: Astrocytes mediate in vivo cholinergic-induced synaptic plasticity. PLoS Biol 2012, 10:e1001259.

26. Deshpande M, Zheng J, Borgmann K, Persidsky R, Wu L, Schellpeper C Ghorpade A: Role of activated astrocytes in neuronal damage: potential links to HIV-1-associated dementia. Neurotox Res 2005, 7:183-192.

27. He J, Choe S, Walker R, Di MP, Morgan DO, Landau NR: Human immunodeficiency virus type 1 viral protein $\mathrm{R}(\mathrm{Vpr})$ arrests cells in the G2 phase of the cell cycle by inhibiting p34cdc2 activity. J Virol 1995, 69:6705-6711.

28. Jones GJ, Barsby NL, Cohen EA, Holden J, Harris K, Dickie P, Jhamandas J, Power C: HIV-1 Vpr Causes Neuronal Apoptosis and In Vivo Neurodegeneration. J Neurosci 2007, 27:3703-3711.

29. Patel CA, Mukhtar M, Pomerantz RJ: Human immunodeficiency virus type $1 \mathrm{Vpr}$ induces apoptosis in human neuronal cells. J Virol 2000, 74:9717-9726

30. Piller SC, Jans P, Gage PW, Jans DA: Extracellular HIV-1 virus protein R causes a large inward current and cell death in cultured hippocampal neurons: implications for AIDS pathology. Proc Natl Acad Sci USA 1998, 95:4595-4600

31. Kitayama H, Miura $Y$, Ando $Y$, Hoshino S, Ishizaka $Y$, Koyanagi $Y$ : Human immunodeficiency virus type $1 \mathrm{Vpr}$ inhibits axonal outgrowth through induction of mitochondrial dysfunction. J Viro/ 2008, 82:2528-2542.

32. Rom I, Deshmane SL, Mukerjee R, Khalili K, Amini S, Sawaya BE: HIV-1 Vpr deregulates calcium secretion in neural cells. Brain Res 2009, 1275:81-86

33. Levy DN, Refaeli Y, MacGregor RR, Weiner DB: Serum Vpr regulates productive infection and latency of human immunodeficiency virus type 1. Proc Natl Acad Sci U S A 1994, 91:10873-10877.

34. Pomerantz RJ: Effects of HIV-1 Vpr on neuroinvasion and neuropathogenesis. DNA Cell Biol 2004, 23:227-238.

35. Mukerjee R, Chang JR, Del Valle L, Bagashev A, Gayed MM, Lyde RB, Hawkins BJ, Brailoiu E, Cohen E, Power C, Azizi SA, Gelman BB, Sawaya BE: Deregulation of microRNAs by HIV-1 Vpr Protein Leads to the Development of Neurocognitive Disorders. J Biol Chem 2011, 286:34976-34985.

36. Gangwani MR, Noel RJ Jr, Shah A, Rivera-Amill V, Kumar A: Human immunodeficiency virus type 1 viral protein $\mathrm{R}(\mathrm{Vpr})$ induces CCL5 expression in astrocytes via PI-3 K and MAPK signaling pathways. J Neuroinflammation 2013, 10:136.
37. Ferrucci A, Nonnemacher MR, Wigdahl B: Extracellular HIV-1 viral protein $\mathrm{R}$ affects astrocytic glyceraldehyde 3-phosphate dehydrogenase activity and neuronal survival. J Neurovirol 2013, 19:239-253.

38. Amini S, Saunders M, Kelley K, Khalili K, Sawaya BE: Interplay between HIV-1 Vpr and Sp1 Modulates p21WAF1 Gene Expression in Human Astrocytes. J Biol Chem 2004, 279:46046-46056

39. Chauhan A, Turchan J, Pocernich C, Bruce-Keller A, Roth S, Butterfield DA, Major EO, Nath A: Intracellular human immunodeficiency virus Tat expression in astrocytes promotes astrocyte survival but induces potent neurotoxicity at distant sites via axonal transport. J Biol Chem 2003, 278:13512-13519.

40. Bruce-Keller AJ, Chauhan A, Dimayuga FO, Gee J, Keller JN, Nath A: Synaptic Transport of Human Immunodeficiency Virus-Tat Protein Causes Neurotoxicity and Gliosis in Rat Brain. J Neurosci 2003, 23:8417-8422

41. Chompre G, Cruz E, Maldonado L, Rivera-Amill V, Porter JT, Noel RJ Jr: Astrocytic expression of HIV-1 Nef impairs spatial and recognition memory. Neurobiol Dis 2013, 49:128-136.

42. Frangakis MV, Kimelberg HK: Dissociation of neonatal rat brain by dispase for preparation of primary astrocyte cultures. Neurochem Res 1984 9:1689-1698.

43. Benice TS, Rizk A, Kohama S, Pfankuch T, Raber J: Sex-differences in agerelated cognitive decline in $\mathrm{C} 57 \mathrm{BL} / 6 \mathrm{~J}$ mice associated with increased brain microtubule-associated protein 2 and synaptophysin immunoreactivity. Neuroscience 2006, 137:413-423.

44. Save E, Poucet B, Foreman N, Buhot MC: Object exploration and reactions to spatial and nonspatial changes in hooded rats following damage to parietal cortex or hippocampal formation. Behav Neurosci 1992 106:447-456.

45. Poucet B: Spatial cognitive maps in animals: new hypotheses on their structure and neural mechanisms. Psychol Rev 1993, 100:163-182.

46. Moon HS, Yang JS: Role of HIV Vpr as a regulator of apoptosis and an effector on bystander cells. Mol Cells 2006, 21:7-20.

47. Borjabad A, Brooks Al, Volsky DJ: Gene expression profiles of HIV-1 infected glia and brain: toward better understanding of the role of astrocytes in HIV-1-associated neurocognitive disorders. J Neuroimmune Pharmacol 2010, 5:44-62.

48. Snyder A, Ross MJ: Murine models of Vpr-mediated pathogenesis. Curr HN Res 2009, 7:129-135.

49. Majno $G$, Joris I: Apoptosis, oncosis, and necrosis: an overview of cell death. Am J Pathol 1995, 146:3-15.

50. Barr ML, Hamilton JD: A quantitative study of certain morphological changes in spinal motor neurons during axon reaction. J Comp Neurol 1948, 89:93-121.

51. Cammermeyer J: Peripheral Chromatolysis after Transection of Mouse Facial Nerve. Acta Neuropathol 1963, 3:213-230.

52. Popratiloff A, Kharazia VN, Weinberg RJ, Laonipon B, Rustioni A: Glutamate receptors in spinal motoneurons after sciatic nerve transection. Neuroscience 1996, 74:953-958.

53. Hanz S, Fainzilber M: Retrograde signaling in injured nerve-the axon reaction revisited. J Neurochem 2006, 99:13-19.

54. Schmitt U, Tanimoto N, Seeliger M, Schaeffel F, Leube RE: Detection of behavioral alterations and learning deficits in mice lacking synaptophysin. Neuroscience 2009, 162:234-243.

55. Masliah E, Achim CL, Ge N, DeTeresa R, Terry RD, Wiley CA: Spectrum of human immunodeficiency virus-associated neocortical damage. Ann Neurol 1992, 32:321-329.

56. Liu Y, Liu H, Kim BO, Gattone VH, Li J, Nath A, Blum J, He JJ: CD4independent infection of astrocytes by human immunodeficiency virus type 1: requirement for the human mannose receptor. J Virol 2004, 78:4120-4133

57. Lopez-Herrera A, Liu Y, Rugeles MT, He JJ: HIV-1 interaction with human mannose receptor ( $\mathrm{hMR}$ ) induces production of matrix metalloproteinase 2 (MMP-2) through hMR-mediated intracellular signaling in astrocytes. Biochim Biophys Acta 2005, 1741:55-64.

58. Fields RD, Stevens-Graham B: New insights into neuron-glia communication. Science 2002, 298:556-562.

59. Barker AJ, Ullian EM: Astrocytes and synaptic plasticity. Neuroscientist 2010, 16:40-50.

60. Atluri VS, Kanthikeel SP, Reddy PV, Yndart A, Nair MP: Human synaptic plasticity gene expression profile and dendritic spine density changes in 
HIV-infected human CNS cells: role in HIV-associated neurocognitive disorders (HAND). PLoS One 2013, 8:e61399.

61. Ota Y, Zanetti AT, Hallock RM: The role of astrocytes in the regulation of synaptic plasticity and memory formation. Neural Plast 2013, 2013:185463.

62. Witcher MR, Kirov SA, Harris KM: Plasticity of perisynaptic astroglia during synaptogenesis in the mature rat hippocampus. Glia 2007, 55:13-23.

63. Langford D, Marquie-Beck J, Almeida S, Lazzaretto D, Letendre S, Grant I, McCutchan JA, Masliah E, Ellis R: Relationship of antiretroviral treatment to postmortem brain tissue viral load in human immunodeficiency virus-infected patients. J Neurovirol 2006, 12:100-107.

64. Rudy JW, Sutherland RJ: The hippocampal formation is necessary for rats to learn and remember configural discriminations. Behav Brain Res 1989, 34:97-109.

65. Prut $L$, Belzung $C$ : The open field as a paradigm to measure the effects of drugs on anxiety-like behaviors: a review. Eur J Pharmacol 2003, 463:3-33.

66. Clarke PG, Clarke S: Nineteenth century research on cell death. Exp Oncol 2012, 34:139-145:

67. Glucksmann A: Cell deaths in normal vertebrate ontogeny. Biol Rev 1951, 26:59-86.

68. Cragg BG: What is the signal for chromatolysis? Brain Res 1970, 23:1-21.

69. Lieberman AR: The axon reaction: a review of the principal features of perikaryal responses to axon injury. Int Rev Neurobiol 1971, 14:49-124.

70. Burnett MG, Zager EL: Pathophysiology of peripheral nerve injury: a brief review. Neurosurg Focus 2004, 16:E1.

71. Clarke JR, Cammarota M, Gruart A, Izquierdo I, Delgado-Garcia JM: Plastic modifications induced by object recognition memory processing. Proc Natl Acad Sci USA 2010, 107:2652-2657.

72. Fiqueiredo CP, Clarke JR, Ledo JH, Ribeiro FC, Costa CV, Melo HM, MotaSales AP, Saraiva LM, Klein WL, Sebollela A, De Felice FG, Ferreira ST: Memantine rescues transient cognitive impairment caused by high-molecular-weight abeta oligomers but not the persistent impairment induced by low-molecular-weight oligomers. J Neurosci 2013, 33:9626-9634

73. Kesner RP, Lee I, Gilbert P: A behavioral assessment of hippocampal function based on a subregional analysis. Rev Neurosci 2004, 15:333-351.

74. Li XG, Somogyi P, Ylinen A, Buzsaki G: The hippocampal CA3 network: an in vivo intracellular labeling study. J Comp Neurol 1994, 339:181-208.

75. Kesner RP: Behavioral functions of the CA3 subregion of the hippocampus. Learn Mem 2007, 14:771-781.

76. Jahn R, Schiebler W, Ouimet C, Greengard P: A 38,000-dalton membrane protein (p38) present in synaptic vesicles. Proc Natl Acad Sci USA 1985, $82: 4137-4141$

77. Wiedenmann B, Franke WW: Identification and localization of synaptophysin, an integral membrane glycoprotein of $\mathrm{Mr} 38,000$ characteristic of presynaptic vesicles. Cell 1985, 41:1017-1028.

78. Edelmann L, Hanson PI, Chapman ER, Jahn R: Synaptobrevin binding to synaptophysin: a potential mechanism for controlling the exocytotic fusion machine. EMBO J 1995, 14:224-231.

79. Alder J, Xie ZP, Valtorta F, Greengard P, Poo M: Antibodies to synaptophysin interfere with transmitter secretion at neuromuscular synapses. Neuron 1992, 9:759-768.

80. Frick KM, Fernandez SM: Enrichment enhances spatial memory and increases synaptophysin levels in aged female mice. Neurobiol Aging 2003, 24:615-626.

\section{Submit your next manuscript to BioMed Central and take full advantage of:}

- Convenient online submission

- Thorough peer review

- No space constraints or color figure charges

- Immediate publication on acceptance

- Inclusion in PubMed, CAS, Scopus and Google Scholar

- Research which is freely available for redistribution 